\title{
INVENTARISASI JENIS TUMBUHAN LIAR BAHAN JAMU TRADISIONAL MASYARAKAT SUMENEP MADURA
}

\section{INVENTORY OF WILD PLANT TYPE OF TRADITIONAL MEDICINE MADURA SUMENEP COMMUNITIES}

\author{
Ismawati $^{1}, \mathbf{R}$. Amilia Destryana ${ }^{2}$ \\ ${ }^{1,2}$ Staf Pengajar Program Studi Teknologi Hasil Pertanian Fakultas Pertanian \\ ${ }^{1,2}$ Program Studi Teknologi Hasil Pertanian Fakultas Pertanian \\ Universitas Wiraraja \\ Jl. Raya Sumenep-Pamekasan Km 5 Patean Sumenep \\ Email : ismawati@wiraraja.ac.id
}

\begin{abstract}
ABSTRAK
Sumenep merupakan salah satu Kabupaten di Pulau Madura yang terkenal dengan jamu tradisonal. Bahan jamu tradisonal masyarakat Sumenep berasal dari tumbuhan liar dan tumbuhan budidaya. Penelitian bertujuan untuk mengidentifikasi jens tumbuhan liar sebagai upaya inventarisasi tumbuhan liar yang dimanfaatkan sebagai bahan jamu tradisional. Penelitian merupakan penelitian eksploratif yang dilakukan dengan cara wawancara mendalam terhadap sumber yang memahami jamu tradisional seperti dukun bayi, tukang pijat dan tukang jamu. Peelitian dilakukan di Kecamatan Dungkek, Batang-Batang dan Gapura. Hasil penelitian menemukan terdapat 22 famili tumbuhan liar yang terdiri dari 29 jenis tumbuhan dengan manfaat yang beragam sebagai bahan jamu tradisional.
\end{abstract}

Kata Kunci: inventarisasi, tumbuhan, jamu, Sumenep, tradisonal

\begin{abstract}
Sumenep is one of the regencies on Madura Island which is famous for traditional herbal medicine. The traditional herbal medicine ingredients of the Sumenep community come from wild plants and cultivation plants. The research aims to identify wild plant species as an effort to inventory wild plants that are used as traditional herbal ingredients. The research is an exploratory study conducted by in-depth interviews with sources who understand traditional herbal medicine such as traditional birth attendants, masseurs and herbalists. The study was conducted in District of Dungkek, Batang-Batang and Gapura. The results found 22 families of wild plants consisting of 29 types of plants with diverse benefits as ingredients of traditional herbal medicine.
\end{abstract}

Keywords: inventory, plants, herbs, Sumenep, traditional

\section{PENDAHULUAN}

Obat tradisional merupakan salah satu kekayaan lokal yang telah diwariskan oleh nenek moyang bangsa Indonesia. Sebagaimana yang dinyatakan Kandowangko dkk dalam (Irawati et al.,2017) bahwa sejak berabad-abad yang lalu, Indonesia telah menggunakan bahan alam sebagai obat-obatan dan hal itu dibuktikan dengan adanya relief candi borobudur yang berbetuk orang sedang 
meracik jamu atau obat dan naskah-naskah lama seperti lontar husodo dan lain - lain.

Sumenep merupakan salah satu Kabupaten di Pulau Madura yang tergolong sebagai wilayah penghasil jamu tradisional. Jamu tradisional madura telah dikenal luas baik dalam maupun luar negeri. Selain jamu madura yang terkenal, masyarakat Sumenep juga memiliki tradisi mengkonsumsi jamu dengan tujuan untuk menjaga kesehatan atau mengkonsumsi jamu dengan tujuan sebagai obat. Hingga saat ini masyarakat Sumenep khususnya masyarakat pedesaan masih memanfatkan tumbuh-tumbuhan sebagai obat tradisional untuk menyembuhkan penyakit ataupun menjaga kesehatan. Sebagai contoh penyakit diare diobati dengan daun meniran atau kesembukan dan lain sebagainya. Berdasarkan hal tersebut maka dapat dikatakan bahwa masyarakat Sumenep telah memiliki pengobatan tradisional yang dapat dibuktikan secara ilmiah.

Beberapa bahan jamu tradisional masyarakat Sumenep terdiri dari tumbuhan yang dibudidaya maupun liar. Untuk bahan jamu yang berasal dari tumbuhan obat yang dibudidayakan misalnya kunyit, jahe atau laos tentunya tetap terjaga kelestariannya karena bahan tersebut selain sebagai obat tradisional, manfaat utamanya adalah sebagai rempah dalam masakan. Akan tetapi bahan jamu yang berasal dari tumbuhan liar akan terancam kepunahan jika tidak dilestarikan.

Salah satu upaya yang dapat dilakukan untuk menjaga kelestarian tumbuhan liar yang bermanfaat sebagai obat tradisional adalah dengan melakukan eksplorasi dan pendataan. Ekplorasi tumbuhan obat liar juga diperlukan untuk identifikasi secara mendalam mengenai anggapan/kepercayaan masyarakat akan khasiatnya kemudian dilanjutkan dengan pembuktian secara ilmiah melalui riset. Eksplorasi merupakan kegiatan yang berupa pelacakan, pencarian dan pengumpulan sumber daya untuk dimanfaatkan serta menghindari terjadinya kepunahan (Zulfahmi, 2010).

\section{METODE PENELITIAN}

Penelitian yang dilakukan berupa penelitian survei eksploratif untuk mendapatkan data yang berupa jenis tumbuhan liar yang dimanfaatkan sebagai bahan jamu tdisional oleh masyarakat Sumenep. Tumbuhan liar dimaksud dalam penelitian adalah tumbuhan yang tidak dipelihara oleh masyarakat baik yang tumbuh di hutan maupun pekarangan atau semak-semak yang tumbuh secara sendiri tanpa ditanam. Tumbuhan liar yang akan diekplorasi berupa tumbuhan yang berupa semak, herba maupun pohon yang tumbuh di wilayah daratan. Eksplorasi merupakan kegiatan tahap awal konservasi yang mencakup kegiatan pelacakan, pengumpulan dan penelitian lebih lanjut mengenai plasma nutfah (Krismawati \& Sabran, 2016).

Penelitian dilakukan di tiga kecamatan yaitu Kecamatan Batangbatang, Kecamatan Gapura dan Kecamatan Dungkek. Ketiga kecamatan tersebut merupakan kecamatan yang berada di bagian timur kabupaten Sumenep dan masyarakatnya masih banyak yang mengkonsumsi jamu serta memproduksi jamu tradisional. Eksplorasi dilakukan dengan cara wawancara mendalam pada informan yang dianggap ahli dalam hal ini dukun bayi dan dukun pijat. Selain wawancara juga akan dilakukan survei dan pengambilan gambar (dokumentasi) pada masing-masing tumbuhan liar di lokasi tumbuh.

Hasil wawancara mendalam dan dokumentasi selanjutnya dianalisis dengan cara identifikasi lanjut mengenai ordo, famili dan spesies. Pada tahap identifikasi dilakukan penelusuran data sekunder berupa buku maupun jurnal ilmiah yang akan dijadikan acuan serta pembanding. Data yang dihasilkan dalam penelitian adalah data deskriptif dari tumbuhan liar yang digunakan sebagai bahan jamu tradisional masyrakat Sumenep Madura. 


\section{HASIL DAN PEMBAHASAN}

Keanekaragaman tumbuhan yang ada di Indonesia merupakan suatu potensi besaar bagi Indonesia menjadi negara sumber bahan pangan maupun obat-obatan. Sekitar 6000 jenis tumbuhan yang liar maupun budidaya telah dimanfaatkan oleh masyarakat lokal sebagai bahan pangan, obat serta pakaian (Walujo, 2011).
Hasil wawancara mengenai jenis tumbuhan liar yang digunakan sebagai bahan jamu tradisional di Kecamatan Gapura, Kecamatan Batang Batang dan Kecamatan Dungkek berjumlah 29 jenis yang berasal dari 22 famili. Adapun jenis tumbuhan liar yang ditemukan di lokasi penelitian sebagaimana disajikan pada Tabel 1.

Tabel 1. Jenis-Jenis Tumbuhan Liar yang Digunakan sebagai bahan Jamu Tradisional Masyarakat Sumenep

\begin{tabular}{|c|c|c|c|c|}
\hline No & Famili & Jenis & Kegunaan & $\begin{array}{c}\text { Bagian yang } \\
\text { Digunakan }\end{array}$ \\
\hline 1 & Rubiaceae & Paederia feotida $L$. & $\begin{array}{l}\text { Meningkatkan } \\
\text { nafsu makan, } \\
\text { mengobati sakit } \\
\text { perut/diare, } \\
\text { mengobati perut } \\
\text { kembung }\end{array}$ & Daun dan batang \\
\hline \multirow[t]{3}{*}{2} & Euphorbiaceae & $\begin{array}{l}\text { Euphorbia } \\
\text { heterophylla L. }\end{array}$ & $\begin{array}{l}\text { Pencuci perut } \\
\text { dan diet }\end{array}$ & Daun \\
\hline & & Acalypha australis & $\begin{array}{l}\text { Mengobati } \\
\text { penyakit kulit } \\
\text { (gatal, bisul) }\end{array}$ & $\begin{array}{l}\text { Daun, bunga dan } \\
\text { batang }\end{array}$ \\
\hline & & Phyllanthus niruri $L$. & $\begin{array}{l}\text { Mengobati sakit } \\
\text { perut karena } \\
\text { diare }\end{array}$ & $\begin{array}{l}\text { Daun, buah dan } \\
\text { batang }\end{array}$ \\
\hline 3 & Meliaceae & Azadiractha indica & $\begin{array}{l}\text { Mengobati } \\
\text { diabetes dan } \\
\text { gatal-gatal }\end{array}$ & $\begin{array}{l}\text { Daun dan kulit } \\
\text { pohon }\end{array}$ \\
\hline \multirow[t]{2}{*}{4} & Asteraceae & Pluchea indica & $\begin{array}{l}\text { Menormalkan } \\
\text { tekanan darah }\end{array}$ & Daun \\
\hline & & $\begin{array}{l}\text { Elephantopus scaber } \\
\text { L. }\end{array}$ & $\begin{array}{l}\text { Menjaga daya } \\
\text { tahan tubuh }\end{array}$ & $\begin{array}{l}\text { Seluruh bagian } \\
\text { tanaman }\end{array}$ \\
\hline 5 & Mimosaceae & Mimosa pudica & $\begin{array}{l}\text { Mengobati } \\
\text { insomia }\end{array}$ & Daun dan batang \\
\hline 6 & Araliaceae & Hedera hibernica & $\begin{array}{l}\text { Menambah } \\
\text { nafsu makan, } \\
\text { mencegah panas } \\
\text { dalam dan } \\
\text { meningkatkan } \\
\text { daya tahan } \\
\text { tubuh }\end{array}$ & Daun \\
\hline 7 & Menispermaceae & Tinospora cordifolia & $\begin{array}{l}\text { Menurunkan } \\
\text { kadar gula darah } \\
\text { dan mengobati } \\
\text { penyakit gatal- } \\
\text { gatal pada kulit }\end{array}$ & Batang tumbuhan \\
\hline
\end{tabular}




\begin{tabular}{|c|c|c|c|c|}
\hline 8 & Lamiaceae & Orthosiphon aristatus & $\begin{array}{l}\text { Kencing batu, } \\
\text { demam dan } \\
\text { stamina }\end{array}$ & $\begin{array}{l}\text { Semua bagian } \\
\text { tumbuhan }\end{array}$ \\
\hline \multirow[t]{2}{*}{9} & Verbenaceae & $\begin{array}{l}\text { Stachytarpheta } \\
\text { jamaicensis }\end{array}$ & $\begin{array}{l}\text { Menjaga } \\
\text { kesehatan }\end{array}$ & Daun dan batang \\
\hline & & Premna cordifolia & $\begin{array}{lr}\text { Mengobati } & \text { sakit } \\
\text { gigi, } & \text { sakit } \\
\text { kepala } & \end{array}$ & Daun \\
\hline 10 & Colchicaceae & Gloriosa superaba & $\begin{array}{l}\text { Demam dan } \\
\text { kencing batu }\end{array}$ & Bunga dan umbi \\
\hline 11 & Acanthaceae & Ruwellia tuberosa $L$. & $\begin{array}{l}\text { Mengobati } \\
\text { asma }\end{array}$ & Daun dan akar \\
\hline \multirow[t]{2}{*}{12} & Muntingiaceae & Muntingia calabura & $\begin{array}{l}\text { Menurunkan } \\
\text { gula darah }\end{array}$ & $\begin{array}{l}\text { Daun dan kulit } \\
\text { pohon }\end{array}$ \\
\hline & & Caesalpinia sappan & \begin{tabular}{lr}
\multicolumn{2}{l}{ Mencegah } \\
panasa dalam \\
dan menjaga \\
daya & tahan \\
tubuh &
\end{tabular} & Kulit pohon \\
\hline 13 & Phyllanthaceae & Phyllanthus emblica & $\begin{array}{l}\text { Mencegah } \\
\text { berbagai macam } \\
\text { penyakit }\end{array}$ & Buah dan daun \\
\hline \multirow[t]{2}{*}{14} & Euphorbiaceae & $\begin{array}{l}\text { Euphorbia } \\
\text { heterophylla L. }\end{array}$ & $\begin{array}{l}\text { Pencuci perut } \\
\text { dan sebagai obat } \\
\text { diet }\end{array}$ & Daun \\
\hline & & Acalypha australis & $\begin{array}{l}\text { Mengobati } \\
\text { penyakit kulit } \\
\text { (gatal, bisul) }\end{array}$ & Daun dan bunga \\
\hline \multirow[t]{2}{*}{15} & Poaceae & Lopatherum gracile & $\begin{array}{l}\text { Meningkatkan } \\
\text { nafsu makan } \\
\text { pada bayi dan } \\
\text { mengobati sakit } \\
\text { perut }\end{array}$ & Akar \\
\hline & & Imperata cylindrica & $\begin{array}{l}\text { Mempercepat } \\
\text { penyembuhan } \\
\text { luka dan } \\
\text { mengobati } \\
\text { panas dalam }\end{array}$ & $\begin{array}{l}\text { Untuk luka } \\
\text { gunakan daun } \\
\text { untuk panas } \\
\text { dalam gunakan } \\
\text { akar }\end{array}$ \\
\hline 16 & Myrtaceae & Syzygium cumini & Mengobati diare & Daun \\
\hline 17 & Acanthaceae & $\begin{array}{l}\text { Andrographis } \\
\text { paniculata }\end{array}$ & $\begin{array}{l}\text { Kencing manis, } \\
\text { gatal-gatal pada } \\
\text { kulit. }\end{array}$ & Daun \\
\hline 18 & Piperaceae & Peperomia pellucid & $\begin{array}{l}\text { Mengbati } \\
\text { diabetes }\end{array}$ & Daun \\
\hline 19 & Portulacaceae & Portulaca oleracea & $\begin{array}{l}\text { Mengobati } \\
\text { tumor dan } \\
\text { menyuburkan } \\
\text { wanita }\end{array}$ & Daun \\
\hline 20 & Caesalpiniaceae & Clitoria ternatea & $\begin{array}{l}\text { Membersihkan } \\
\text { dan } \\
\text { menjernihkan } \\
\text { mata bayi }\end{array}$ & Bunga \\
\hline
\end{tabular}




$\begin{array}{llll}21 & \text { Meliaceae } & \text { Azadiractha indica } & \begin{array}{l}\text { Mengobati } \\ \text { diabetes dan } \\ \text { gatal-gatal } \\ \text { Melancarkan } \\ \text { darah nifas dan } \\ \text { haid }\end{array} \\ & \text { Fabaceae } & \text { Indigofera tinctoria } & \\ & & & \\ & & \end{array}$

Dari ke 29 jenis tumbuhan liar sebagaimana pada Tabel 1 beberapa telah diteliti kandungan dan kemanfaatannya sebagai obat yang diantaranya memiliki kandungan antibakteri, antioksidan serta manfaat lainnya. Salah satu diantarnya adalah daun buas-buas (Premna cordifolia). Ekstrak etanol daun buas buas mengandung senyawa flavonoid, saponin, fenol dan alkaloid. Keempat senyawa tersebut merupakan antioksidan alami yang disintetis oleh tumbuhan dan tubuh manusia tidak dapat mensintesis sendiri (Garvita, 2015; Kurniati, 2013).Satu tumbuhan yang mengandung antimalaria adalah sirih cina (Peperomia pellucid) yang diekstrak menggunakan n-heksan, metanol dan etil asetat (Bialangi et al., 2016).

Jenis tumbuhan liar yang digunakan sebagai bahan jamu oleh masyarakat Sumenep berdasarkan perawakannya terdiri dari 4 jenis yang diantaranya adalah lebih dari 5 meter dan disebut pohon, 2-5 meter disebut dengan jenis perawakan perdu, 1-2 meter yang disebut dengan jenis perawakan semak dan kurang dari 1 meter yang disebut dengan jenis perawakan herba. Penggolongan jenis tumbuhan berdasarkan perawakan mengacu pada penggolongan dalam penelitian jenis tumbuhan obat pada hutan pendidikan Kabupaten Karo Sumatera Utara (Sembiring et al., 2015).

Adapun jenis tumbuhan yang termasuk gologan herba berjumlah 9 yaitu dari famili lamiceae, mimosaceae, poaceae, cyperaceae, piperaceae, portulaceae, polypodiaceae, cyperaceae dan fabaceae. Tumbuhan yang termasuk dalam perawakan pohon berjumlah 7 yang terdiri dari famili meliaceae, mirtaceae, caesalpiniaceae, rubiaceae, montingiacea, araliceae dan phyllanthaceae. Adapun yang termasuk golongan perawakan semak berjumlah 3 yang diantaranya merupakan famili asteracea, euphorbiceae, verbenaceae sedangkan tumbuhan perawakan perdu ada 3 yaitu famili achantaceae, colchicaceae dan menispermacea.

Menurut masyarakat Sumenep Madura Lophatherum gracile bermanfaat menaambah nafsu makan bayi dan mengobati sakit perut. Salah satu jenis rumput yang tergolog dalam perawakan herba yaitu rumput teki (Lophatherum gracile) yang telah dimanfaatkan sebagai obat oleh masyarakat cina karena memiliki aktivitas antibakteri antipirek dan antiiuretik. Adapun ciri perawakan dari Lophatherum gracileyaitu daun berbentuk lanset dengan panjang $5-20 \mathrm{~cm}$ dan memiliki lebar $1-3,5 \mathrm{~cm}$. Permukaan daun berwarna hijau yang cerah atau hijau kekuningan. Bentuk daun keriput serta keriting (Wulandari et al., 2017).

Meniran (Phyllanthus niruri L) dimasyakat Kaupaten Sumenep dipercaya dan dimanfaatkan sebagai obat diare. Masyarakat Sumatera Utara juga memanfaatkan Phyllanthus niruri $L$. sebagai tumbuhan obat yang dapat 
mengatasi penyakit, sakit pinggang, antidiabetes, hepatitis dan penyakit anjing gila serta dapat melindungi zel hati dari racun (Kinho et al., 2011).Tumbuhan liar yang juga termasuk famili euphorbiceae yaitu Acalypha australis $L$. yng dipercaya oleh masyarakat Sumenep dalam mengobati penyakit kulit ternyata diketahui dapat menurunkan gula darah mencit dengan dosis $1000 \mathrm{mg} / \mathrm{kgBB} / \mathrm{hari}$ (Ocktarini, 2010). Acalypha australis L. juga dipercaya oleh masyarakat Sumatera Utara dapat mengobati berak darah, disentri pendarahan dan luka luar (Kinho et al., 2011).

Salah satu jenis tumbuhan liar Kabupaten Sumenep yang dimanfaatkan bunganya adalah telang (Clitoria ternatea). Jenis tanaman Clitoria ternatea dikenal sebagai obat tetes mata pada bayi untuk membersihkan dan menjernihkan mata. Kegunaan bunga telah ternyata juga telah dinyatakan oleh Triyanto bahwa telang selain dapat dimanfaatkan sebagai pewarna pada makanan juga dapat dimanfaatkan sebagai obat tetes pada mata (Defiani \& Kriswiyanti, 2019).

\section{KESIMPULAN}

Jenis tumbuhan liar yang ditemukan di Kabupaten Sumenep tepatnya di Kecamatan Dungkek, Batang-Batang dan Gapura berjumlah 29 jenis yang berasal dari 22 famili. Dari 22 famili tumbuhan liar ditemukan 9 tumbuhan merupakan famili yang berasal dari golongan yang berperawakan herba, 7 tumbuhan berperawakan pohon, 3 tumbuhan berperawakan semak dan 3 tumbuhan berperawakan perdu.

\section{SARAN}

Bagi penelitian selanjutnya dianjurkan untuk meneliti dan membuktikan secara ilmiah fitokimia dari beberapa tumbuhan liar yang secara tradisional memiliki khasiat obat yang belum dikaji dan dibuktikan agar dapat mendukung pengembangan obat herbal di Indonesia.

\section{UCAPAN TERIMA KASIH}

Atas tersusunnya artikel ini, disampaikan terima kasih kepada Lembaga Penelitian dan Pengabdian kepada Masyarakat Universitas Wiraraja yang telah mendanai pelaksanaan penelitian pada tahun pendanaan 2019 .

\section{DAFTAR PUSTAKA}

Bialangi, N., Mustapa, M. A., Salimi, Y. K., Widiantoro, A., \& Situmeang, B. (2016). Antimalarial activity and phitochemical analysis from Suruhan (Peperomia pellucida) extract. Jurnal Pendidikan Kimia, 8(3), 183-187.

Defiani, M. R., \& Kriswiyanti, E. (2019). Floral Diversity in Mincidan Village, Klungkung, Bali To Support Ecotourism. Simbiosis, 7(1), 14. https://doi.org/10.24843/jsimbiosis. 20 19.v07.i01.p04

Garvita, R. V. (2015). Pemanfaatan tumbuhan obat secara tradisional untuk memperlancar persalinan oleh suku dayak meratus di kalimantan selatan, 13(November), 51-58.

Irawati, D., Arini, D., Mongondow, B., \& Utara, S. (2017). Pengetahuan Lokal Masyarakat Sulawesi Utara Sebagai Bahan Obat Tradisional the Local Knowledge of Community in North 
Sulawesi on Forest Tress Used As a Traditional Medicine ), 19(2), 161174.

Kinho, J., Irawati, D., Arini, D. W. I., Halawane, J., Nurani, L. I. S., Kafiar, Y., \& Karundeng, M. C. (2011). Tumbuhan Obat Tradisional Di Sulawesi Utara. Manado.

Krismawati, A., \& Sabran, M. (2016). Pengelolaan Sumber Daya Genetik Tanaman Obat Spesifik Kalimantan Tengah. Buletin Plasma Nutfah, 12(1), 16.

https://doi.org/10.21082/blpn.v12n1.2 006.p16-23

Kurniati, R. I. Uji Aktivitas Antioksidan Fraksi Etanol Daun Buas-Buas (Premna cordifolia Linn.) Dengan Metoda DPPH (2,2-difenil-1pikrilhidrazil), Skripsi 1-43 (2013).

Ocktarini, R. (2010). Pengaruh Ekstrak Herba Anting-Anting(Acalypha Australis L.) Terhadapkadar Glukosa Darahmencit Balb/C Induksi Streptozotocin. Retrieved from https://eprints.uns.ac.id/3154/

Sembiring, E. F. B., Indriyanto, \& Duryat. (2015). Keragaman Jenis Tumbuhan Obat di Hutan Pendidikan Universitas Sumatera Utara Kawasan Taman Hutan Raya Tongkoh Kabupaten Karo Sumatera Utara. Jurnal Sylva Lestari, 3(2), 113-122. https://doi.org/10.23960/js123113-122

Walujo, E. B. (2011). Keanekaragaman hayati untuk pangan. Makalah KIPNAS X, 1-9.

Wulandari, Y. D., Sari, S. M., \& Mahanal, S. (2017). Identifikasi Tumbuhan Suku Poaceae Sebagai Suplemen Matakuliah Keanekaragaman Tumbuhan. Jurnal Pendidikan, 2(1), 97-103.

Zulfahmi, B. S. (2010). Eksplorasi tanaman obat potensial di kabupaten kampar. Jurnal Agroteknologi, 1, 3138 . 